\title{
CONTRAÇÃO DE FERIDAS APÓS COBERTURA COM SUBSTITUTOS TEMPORÁRIOS DE PELE
}

\author{
CONTRACTION OF WOUND AFTER COVER \\ WITH TEMPORALY SKIN SUBSTITUTES
}

\section{Maria Cristina Oliveira Coelho $^{1}$ Cleuza Maria de Faria Rezende ${ }^{2}$ Ana Paula Monteiro Tenório ${ }^{3}$}

\section{RESUMO}

\begin{abstract}
Feridas experimentais foram recobertas com substitutos temporários de pele produzidos com poliuretano, hidrocolóide, hemicelulose e vaselina e com gaze, para avaliação do cálculo da área e percentual de contração ao $7^{\circ}, 14^{0}$ e $28^{\circ}$ dias de evolução. O curativo hidrocolóide proporcionou uma redução da área inicial ao sétimo dia, não se observando diferenças significativa entre os tratamentos nos períodos seguintes.
\end{abstract}

Palavras-chave: contração, ferida, curativo, cicatrização.

\section{SUMMARY}

Experimentals wounds have covered with temporary skin substitutes, made of poliurethane, hidrocolloid hemicellulose and vaseline and gauze in order to avaliate the area and contraction percentual at the $7^{\text {th }}, 14^{\text {th }}$ and $28^{\text {th }}$ days. The hidrocolloidal dressing provided reduction of the initial area at the $7^{\text {th }}$ day and no significant difference was observed on the other periods.

Key words: contrarction, wound, dressing, healing.

\section{INTRODUÇÃO}

A pele está exposta freqüentemente a traumatismos que desencadeiam soluções de continuidade com perdas extensas de tecidos, resultando em cicatrização, na tentativa de restabelecer sua integridade funcional.

As feridas lacerantes, úlceras, queimaduras, exérese de neoplasias e correções cirúrgicas de defeitos cutâneos exigem tratamento especializado para se obter retorno funcional e anatômico da região. A extensão da perda cutânea dificulta ou até mesmo impossibilita a aproximação das bordas, ocorrendo a cicatrização por segunda intenção, que é um processo mais lento, produzindo muitas vezes cicatrizes extensas, retração cicatricial e elevação do custo do tratamento.

As feridas abertas, com ou sem perda de tecido, apresentam problemas clínicos diferentes das feridas incisas e suturadas. Embora os processos morfológicos e químicos básicos, que atuam na ferida fechada, sejam os mesmos nas feridas abertas em cicatrização, a contração torna-se um aspecto importante nas feridas abertas, e a epitelização assume um papel proeminente. Os dois processos parecem ser independentes (MADDEN \& AREM, 1991).

As fases finais do processo cicatricial são constituídas pela contração e aumento da resistência da cicatriz. A contração é a redução de parte ou de toda a área da ferida aberta, ocorrendo de forma centrípeta, a partir das bordas da lesão (VAN WINKLE, 1967), sendo provocada pelos filamentos de actina (POPE, 1993) dos miofibroblastos e pelo rearranjo das moléculas de colágeno (ANDERSON, 1996).

A contração da ferida é favorecida nos locais onde a pele é mais frouxa e móvel, como a pele do tronco (RAMSEY et al., 1995). Quanto mais

\footnotetext{
${ }^{1}$ Médico Veterinário. Aluno do Curso de Doutorado, Escola de Veterinária, Universidade Federal de Minas Gerais (UFMG), Belo Horizonte, MG. Prof. Assist, Depto Medicina Veterinária, Universidade Ferderal Rural de Pernanbuco (UFRPE), Av. Dom Manoel, s/n. Dois Irmãos, 52171-900, Recife, PE. E-mail: cgzen@truenet.com.br. Autor para correspondência.

${ }^{2}$ Médico Veterinário. Doutor, Professor Adjunto, Departamento de Clínica e Cirurgia Veterinárias, UFMG.

${ }^{3}$ Médico Veterinário, Aluno do Curso de Mestrado em Medicina Veterinária, UFRPE.
} 
móvel for a pele, maior será a intensidade de contração da ferida. A mobilidade cutânea depende da direção das "linhas de Langer", que é determinada pela disposição do sistema fibrilar da pele, sobretudo das fibras elásticas. A distensão máxima acontece em direção transversal às linhas de Langer, motivo pelo qual a contração da ferida ocorre nesta direção (ALGOWER, 1977). A orientação da ferida com relação às linhas normais de tensão da pele, ou seja, em ângulo reto com o músculo adjacente é, segundo KOOPMANN (1995), o fator local mais importante para a cicatrização. Segundo o autor, as feridas que cruzam as linhas de Langer são difíceis de cicatrizar e apresentam tendência a se tornarem hipertróficas.

O mecanismo de contração inicia-se precocemente durante a cicatrização e evolui após a maturação da cicatriz. A força tênsil da cicatriz depende da quantidade de colágeno, no início e na fase final do processo, da mudança do tipo de colágeno produzido e do aumento das ligações covalentes entre as moléculas de colágeno (CHANDRASOMA \& TAYLOR, 1993).

Os miofibroblastos induzem a ferida a se contrair 0,60 a $0,75 \mathrm{~mm}$ por dia (KOOPMANN, 1995), cessando quando as bordas do ferimento se justapõem (inibição de contato), ou quando a tensão na pele circunjacente à ferida excede à força contrátil do miofibroblasto ou, ainda, quando há acúmulo e maturação do colágeno, associados à diminuição dos miofibroblastos (POPE, 1993). A redução dos capilares ocorre entre a $6^{\mathrm{a}}$ e a $18^{0}$ semana e o processo de remodelagem está completo entre 6 e 18 meses (KOOPMANN, 1995).

Nas cicatrizes cutâneas, a coloração passa, gradualmente, do rosado ao esbranquiçado devido à redução da vasculatura no tecido (MODOLIN, 1992) e pela não regeneração dos elementos melânicos (MODOLIN \& BEVILACQUA, 1992). A pele torna-se também mais densa, como resultado da perda de líquido e de volume (KOOPMANN, 1995).

A seleção de um curativo apropriado para favorecer a cicatrização de ferida demanda conhecimento das diversas categorias disponíveis, devendo-se entender os princípios de desenvolvimento dos curativos, como também as qualidades de cada produto individualmente. Os primeiros relatos referemse ao emprego de materiais plásticos como o polivinil e o polietileno, evoluindo até os curativos atuais como os hidrocolóides, hidrogel, películas, esponjas e os alginatos - conhecidos como sais de ácido algínico (CHOATE, 1994). As películas são produzidas com filme transparente de poliuretano e proporcionam, juntamente com os hidrocolóides, um incremento na cicatrização e diminuição da dor (BARBUL $\boldsymbol{e t}$ al., 1990).
O tipo de curativo varia com a natureza, localização e tamanho da ferida. A seleção deve ser feita com base nas propriedades físicas de proteção e o tipo de perda cutânea. São recomendados para cobertura de feridas abertas, recentes ou crônicas, leitos doadores de enxertos e cobertura de feridas por primeira intenção e após aplicação dos enxertos. Seu uso induz a reação inflamatória e contribui com a cicatrização por ativar macrófagos ou fibroblastos, produção de fatores de crescimento e outros mediadores do processo de reparação (CHAVPIL $\boldsymbol{e t}$ al., 1990). De modo geral, o curativo adequado pode resultar em uma cicatrização melhor, tanto estética como funcionalmente, desde que os princípios gerais dos cuidados com as feridas, limpeza, umidade e cobertura sejam mantidos (ANDRADE $\boldsymbol{e t} \boldsymbol{a l} ., 1992$ ).

Uma vantagem adicional é que os curativos mais recentes são transparentes, o que permite a observação diária do aspecto da ferida, possibilitando a detecção precoce de complicações. Os riscos e desvantagens dos curativos oclusivos incluem a dificuldade de aderir às áreas cruentas e às áreas irregulares, e o acúmulo de secreção sob o mesmo. Todas estas desvantagens são mais teóricas do que práticas, pois a incidência de infecção é menor quando se utiliza esse tipo de curativo e a aderência é, às vezes, indesejável, porque a cada troca do curativo podem ser lesadas células epiteliais recémformadas (ANDRADE $\boldsymbol{e t}$ al., 1992).

O curativo hidrocolóide é um substituto temporário de pele, sintético, oclusivo, consiste de uma lâmina constituída de duas camadas, uma externa, confeccionada com poliuretano e outra interna, adesiva e formada por partículas hidrocolóides e polímeros hidrofóbicos. Quimicamente, esta camada consiste em uma complexa mistura de gelatina, pectina e carboximetilcelulose de sódio incorporada a poliisobutileno com revestimento externo de espuma de poliuretano, o que fornece superfície oclusiva (STRACHAN, 1996).

As vantagens dos hidrocolóides consistem na sua capacidade de promover a decomposição da fibrina, aumentando a proliferação de queratinócito (estímulo da migração epitelial), de absorver grande volume de exsudatos e proteger contra microorganismos. Devido à superfície impermeável, não há necessidade de trocas após banho (CHOATE, 1994). Está indicado para aplicação em úlceras, perda de pele total, queimaduras, sítios doadores de enxertos (JETER \& TINTLE, 1991), lesões com tecido de granulação, feridas com cavidade, crostas, tecido necrótico ou exsudato moderado (COCKBILL \& TURNER, 1995). As desvantagens incluem a possibilidade de maceração ao redor da falha cutânea e impossibilidade de observação da ferida, por ser um 
material opaco. A remoção precoce pode ocasionar destruição do tecido epitelial neoformado (CHOATE, 1994).

Os curativos semi-permeáveis são usados em feridas limpas e superficiais, úlceras de estágio I ou II e feridas com contaminação fecal ou urinária (ANDRADE $\boldsymbol{e t} \boldsymbol{a l} .$, 1992). São representados pelas películas de poliuretano que contêm uma camada adesiva delgada $(<0,2 \mathrm{~mm})$, elástica e transparente. Possuem a vantagem de ser confortáveis e transparentes e a desvantagem de exigir certa habilidade de aplicação, uma vez que a película adere sobre si mesma (CHOATE, 1994).

Os substitutos temporários de pele podem também ser de origem biológica, neste trabalho representado pela película de hemicelulose. São usados como cobertura temporária de feridas abertas, utilizando-se material biológico que não a pele do paciente, exercendo efeitos fisiológicos e mecânicos. Possuem as propriedades desejáveis para um curativo, como proteção da ferida, controle microbiano e incremento da cicatrização (ANDRADE $\boldsymbol{e} \boldsymbol{t} \boldsymbol{a l}$., 1992).

Devido ao alto percentual de traumatismos que acometem os cães ocasionando perda cutânea extensa, e a importância do mecanismo de contração para o retorno funcional e anatômico, este trabalho teve como objetivo estudar a redução da área de feridas recobertas com substitutos temporários de pele produzidos com poliuretano, hidrocolóide e hemicelulose.

\section{MATERIAL E MÉTODOS}

Foram utilizados 30 cães, adultos, 13 machos e 17 fêmeas, sem raça definida, com peso entre 9 e $13 \mathrm{~kg}$ e considerados clinicamente sadios após exame clínico sistemático. Todos os animais apresentaram ausência de alterações dermatológicas e foram submetidos a hemogramas e exames parasitológicos de fezes.

Para o delineamento experimental, os animais foram divididos aleatoriamente em três grupos contendo dez cães cada. A variação entre os grupos constou do tempo de pós-operatório requerido para avaliação da área da ferida. Os cães do grupo "A" permaneceram em observação durante 7 dias, do grupo "B" por 14 dias e os animais do grupo "C" durante 28 dias.

Após jejum hídrico e alimentar de doze horas, os cães foram encaminhados à área de cirurgia, pesados e pré-anestesiados com sulfato de atropina $^{\mathrm{a}}$, na dose de $0,044 \mathrm{mg} / \mathrm{kg}$, via subcutânea, recebendo 15 minutos após o cloridrato de xilazina ${ }^{\mathrm{b}}$, na dose de $0,2 \mathrm{mg} / \mathrm{kg}$, via intramuscular. Após tricoto- mia da região torácica lateral direita e esquerda, procedeu-se anestesia com etomidato ${ }^{\mathrm{c}}, 0,1 \mathrm{mg} / \mathrm{ml}$, via venosa. Todos os animais foram mantidos em venóclise com administração de cloreto de sódio a $0,9 \%$.

Com o cão posicionado em decúbito ventral, a anti-sepsia do campo operatório foi feita com polivinil-pirrolidona-iodo seguida de álcool etílico a $70^{\circ}$. Os panos de campo foram posicionados de forma rotineira e com auxílio de moldes de papel adesivos, previamente confeccionados e esterilizados. Quatro áreas foram demarcadas na região torácica, duas de cada lado do tórax e distantes $10 \mathrm{~cm}$ entre si. A pele foi incidida com lâmina de bisturi e divulsionada da tela subcutânea com tesoura romba até sua ressecção, produzindo uma falha cutânea de $6,25 \mathrm{~cm}^{2}$. A hemostasia da área foi realizada por compressão digital sobre os capilares.

Cada ferida recebeu o substituto temporário de pele de acordo com a metodologia estabelecida, considerando-se a ferida controle a situada caudalmente ao tórax na região esquerda, recebendo aplicação tópica de pomada de vaselina ${ }^{\mathrm{d}}$ e gaze . Cranialmente, nessa mesma região, aplicou-se sobre a falha produzida o curativo hidrocolóide ${ }^{\mathrm{e}}$. No lado oposto do tórax, a ferida caudal recebeu a película de hemicelulose ${ }^{\mathrm{f}}$ e a cranial, a lâmina de poliureta$\mathrm{no}^{\mathrm{g}}$. Todos os substitutos temporários ultrapassaram as bordas das feridas em cerca de $1 \mathrm{~cm}$ sem produzir tensão ou enrugamento, utilizando gaze e pressão para aplicação e fixação, iniciando do centro para as extremidades. Os curativos foram mantidos no interior de suas embalagens esterilizadas e abertos apenas no momento de sua aplicação.

O tórax foi envolvido com atadura de crepom, seguido de proteção com curativo em malha ${ }^{\mathrm{h}}$, utilizando-se também colar elizabetano durante todo o período experimental. Imediatamente após a cirurgia, os animais receberam enrofloxacina ${ }^{\mathrm{i}}$, na dose de $2,5 \mathrm{mg} / \mathrm{kg}$, via intramuscular e a cada 24 horas até o sétimo dia de pós-operatório. As avaliações clínicas foram feitas com 24 horas após a cirurgia e, diariamente, até o período final de cada grupo, observando-se o estado geral do animal, apetite, temperatura corporal e os parâmetros fisiológicos.

As trocas da atadura de crepom e curativo em malha foram realizadas com 24 horas após e a cada quatro dias. Na falha cutânea recoberta com gaze e vaselina, o curativo foi trocado diariamente. Todas as feridas foram avaliadas, fotografadas e medidas as suas bordas através de régua milimetrada no período final dos grupos. Para o cálculo da área das feridas, foi realizada a medição de suas bordas, observando-se o maior e menor diâmetro. A partir destes elementos, a área foi calculada, utilizando-se 
a equação matemática recomendada por PRATA $\boldsymbol{e t}$ al. (1988), $\mathrm{A}=\pi$. R.r, onde " $\mathrm{A}$ " representa a área, " $R$ " o raio maior e " $r$ " o raio menor da lesão. O cálculo do grau de contração foi expresso em percentual, utilizando-se as equações matemáticas propostas por Ramsey et al. (1995), $100 \times\left(\mathrm{W}_{\mathrm{o}}-\mathrm{W}_{\mathrm{i}}\right) /$ $\mathrm{W}_{\mathrm{o}}=\mathrm{M} \pm \mathrm{DP}$, onde : $\mathrm{Wo}=$ área inicial da ferida; $\mathrm{W}_{\mathrm{i}}$ = área da ferida no dia da biópsia ( 7,14 e 28 dias), $\mathrm{M}=$ média e $\mathrm{DP}=$ desvio padrão.

Para a análise estatística dos resultados, utilizou-se o teste não paramétrico de KruskalWallis e as comparações das médias através do teste $\mathrm{T}$ de Student.

\section{RESULTADOS E DISCUSSÃO}

Quatro feridas apresentaram área maior do que a inicial ao sétimo dia de pós-operatório. Destas, três foram recobertas com curativo biológico e uma pertencia ao grupo controle. Ao $14^{0} \mathrm{dia}$, todas as falhas cutâneas apresentavam-se com tamanho menor com relação ao dia zero. $\mathrm{O}$ aumento da área da ferida ocorreu devido à retração das bordas da lesão por ação das linhas de força, conhecidas como linhas de Langer, determinadas pelos sistemas fibrilares da pele, principalmente das fibras elásticas. Para a produção das feridas de forma quadrada, a pele foi incidida no sentido longitudinal e transversal, determinando aumento da área, devido à distensão provocada pela incisão transversal às linhas de Langer, conforme ressaltou ALGOWER (1977).

$\mathrm{Na}$ análise da ferida, no momento anterior à biópsia, observou-se, ao sétimo dia, que a média da área das feridas recobertas foi de 3,93; 3,15; 4,53 e $4,63 \mathrm{~cm}^{2}$ para as lesões tratadas com curativo de poliuretano, hidrocolóide, biológico e vaselina com gaze, respectivamente. A diminuição da área da lesão ocorreu devido ao mecanismo de contração que, juntamente com a epitelização, caracteriza a cicatrização por segunda intenção, conforme descrito por MADDEN \& AREM (1991). Alinhados nos eixos de contração e produzindo movimentos centrípetos das bordas da ferida (VAN WINKLE, 1967; CHANDRASOMA \& TAYLOR, 1993), os miofibroblastos, através de seus filamentos de actina (POPE, 1993), são capazes de reduzir a área da lesão facilitando a epitelização. A contração do tecido de granulação, segundo McGRAFT (1982), também estaria associada à ação mediadora das prostaglandinas.

Com relação à contração diária, observouse que ocorreu redução de $0,33 \mathrm{~mm}^{2}$ nas feridas recobertas com lâmina de poliuretano, $0,44 \mathrm{~mm}^{2}$ com hidrocolóide, $0,24 \mathrm{~mm}^{2}$ com biológico e $0,23 \mathrm{~mm}^{2}$ nas lesões que receberam vaselina e gaze . Avalian- do-se os resultados, pôde-se verificar que o substituto temporário de hidrocolóide reduziu a área da lesão em 50\%. Entretanto, de acordo com KOOPMANN (1995), os miofibroblastos induzem à contração de 0,60 a $0,75 \mathrm{~mm}$ por dia e, quando há produção de colágeno e arranjo das suas moléculas, os miofibroblastos diminuem em número, quando se observa a relação do mecanismo de contração com a maturação do colágeno (ANDERSON, 1996). Como a contração ocorre de forma centrípeta, as feridas, que inicialmente eram quadradas, reduziram seu tamanho, originando margens irregulares sem figura geométrica definida, não permitindo, portanto, o cálculo linear da velocidade de contração, como exposto por KOOPMANN (1995). Neste trabalho, optou-se pelo cálculo da redução da área, o que permitiu um resultado comparativo entre os curativos.

Ao $14^{\circ}$ dia, o valor médio da área das feridas foi de 0,$32 ; 0,55 ; 0,61$ e $0,57 \mathrm{~cm}^{2}$ para as lesões recobertas com o curativo de poliuretano, hidrocolóide, biológico e vaselina com gaze. Avaliando-se os resultados, pôde-se visualizar uma redução acentuada da área lesionada entre o $7^{\circ}$ e o $14^{0} \mathrm{dia}$, demonstrando que o mecanismo de contração encontra-se mais intenso neste período. Calculando-se a média diária de contração de cada ferida, observouse que as lesões recobertas com o poliuretano reduziram sua área em $0,42 \mathrm{~mm}^{2}$ e os demais em $0,40 \mathrm{~mm}^{2}$. Quando comparados os resultados obtidos com 7 e 14 dias, verifica-se que, o substituto de pele hidrocolóide apresentou uma redução da área em 0,44 e $0,40 \mathrm{~mm}^{2}$, respectivamente. Isso, provavelmente, deve-se ao aparecimento precoce dos miofibroblastos nesta fase inicial do processo, demonstrando um incremento na evolução da cicatrização com relação aos outros curativos, como ressaltaram HUCHINSON e McGUCKIN (1990), afirmando que a umidade produzida pelo curativo oclusivo é capaz de favorecer a migração de células epidérmicas, aumentando a vascularidade e o número de miofibroblastos. Como o período de 14 dias corresponde, segundo a maioria dos autores consultados, à fase proliferativa com a presença do fibroblasto e, conseqüentemente, do miofibroblasto, correpondendo a $30 \%$ da população (MODOLIN \& BEVILACQUA, 1992), é de se esperar que a contração seja mais pronunciada neste período, reduzindo a área cruenta da ferida, conforme assinalaram CARRICO et al. (1984). Tal ocorrência deve-se à capacidade contrátil dessas células sobre o tecido de granulação, conforme RUNGGER-BRANDIE \& GABBIANI (1983), participando também da adesão celular e reabsorção da matriz extracelular (BURRIDGE, 1981). É interessante observar que, 
entre 7 e 14 dias, a contração diária aumentou em todas as lesões, com exceção da coberta com hidrocolóide, que diminuiu de 0,44 para $0,37 \mathrm{~mm}^{2}$. As demais mostraram contração diária de 0,$51 ; 0,56$ e $0,58 \mathrm{~mm}^{2}$, respectivamente, para as feridas recobertas com poliuretano, biológico e vaselina com gaze. Como o maior aumento ocorreu nas feridas controle e biológico, seguida do poliuretano, no período de 7 a 14 dias, é de se esperar que os miofibroblastos sejam encontrados em maior número neste período. A ferida recoberta com o hidrocolóide, considerado oclusivo, segundo STRACHAN (1996), por ter tido uma contração maior nos sete primeiros dias, demonstrou uma fase mais avançada da cicatrização com relação aos demais grupos, diferindo dos resultados encontrados por MORGAN et al. (1994) que obteve cicatrização mais rápida da área da ferida com o substituto de pele semi-oclusivo.

Com 28 dias, a área média das feridas foi de 0,$18 ; 0,39 ; 0,22$ e $0,32 \mathrm{~mm}^{2}$ para as lesões recobertas com o substituto temporário de poliuretano, hidrocolóide, biológico e vaselina com gaze, respectivamente. $\mathrm{O}$ valor da contração diária, considerando o período total, foi de $0,20 \mathrm{~mm}^{2}$ para as lesões recobertas com o hidrocolóide e $0,21 \mathrm{~mm}^{2}$ para o poliuretano, biológico e controle. Avaliando-se os resultados, é possível notar que não houve diferença entre os tratamentos, quando se considera o período total de cicatrização. Estabelecendo apenas o período entre 14 e 28 dias, a contração mostrou os seguintes resultados: 0,$02 ; 0,02 ; 0,05$ e $0,03 \mathrm{~mm}^{2}$ para as feridas tratadas com poliuretano, hidrocolóide, biológico e vaselina com gaze, respectivamente. Com 28 dias, ocorre a fase de maturação da cicatrização, que corresponde à diminuição do número de fibroblastos e miofibroblastos (KOOPMANN, 1995), com deposição e remodelação do colágeno (MODOLIN, 1992) que substitui o mecanismo de contração realizado pelos miofibroblastos (CHANDRASOMA \& TAYLOR, 1993).

Analisando todos os intervalos de tempo no pós-operatório, ou seja, do dia zero ao $7^{\circ}$, deste ao $14^{0} \mathrm{e}$, do $14^{0}$ ao $28^{0}$ dia, observa-se que a maior redução da área da ferida ocorreu nas feridas recobertas com o hidrocolóide, apenas no período inicial de 7 dias; diminuindo na fase seguinte e assemelhando-se às demais a partir de 14 dias. Com estes resultados, é possível admitir que o curativo hidrocolóide proporcionou um incremento no processo cicatricial, provavelmente devido ao meio proporcionado pelo curativo que, segundo CHAVPIL et al. (1990), induz a reação inflamatória, contribuindo com a chegada mais rápida dos polimorfonucleares e macrófagos. A seguir, o processo equiparou-se com os demais tratamentos com relação à contração.
Todas as feridas foram produzidas de forma similar na região torácica $\mathrm{e}$, portanto, submetidas à mesma tensão da pele, a área foi escolhida seguindo orientação de RAMSEY et al. (1995) quando cita que a contração das feridas é favorecida na pele mais frouxa e móvel, como a do tronco.

Aplicando-se a fórmula estabelecida para o cálculo do percentual médio de contração, foi possível observar os seguintes resultados nos dias 7, 14 e 28 : feridas recobertas com poliuretano apresentaram 37,042; 93,30 e 97,99\% da redução da área inicial; curativo hidrocolóide, 55,486; 94,563 e 93,616 \%; lâmina biológica, 26,952; 95,111 e $96,410 \%$ e vaselina com gaze, 25,830; 94,933 e $94,774 \%$. Considerando a relação inversa entre a redução diária da área da ferida e o percentual de cicatrização no processo cicatricial normal, observase que quanto mais próximo do fechamento da falha cutânea, menor a força de contração, demonstrando que apesar do arranjo da molécula do colágeno exercer efeito na diminuição da área da ferida, a ação dos miofibroblastos durante a fase proliferativa foi maior, não diferindo, entretanto, o aspecto clínico da lesão, que se apresentou sempre de forma irregular e com redução centrípeta.

Todas as feridas foram produzidas de forma asséptica, com exérese de pele total, procurando-se seguir as orientações de ANDRADE $\boldsymbol{e t}$ al. (1992) e JETER \& TINTLE (1991). As trocas foram realizadas a cada quatro dias, a fim de não ocorrer trauma ao tecido epitelial como citado por CHOATE (1994), e os curativos permaneceram após a formação do tecido de granulação, o que, segundo COCKILL \& TURNER (1995), é também uma condição propícia para a aplicação dos substitutos de pele.

$\mathrm{Na}$ análise microscópica do processo cicatricial, observou-se que a fase inflamatória, como era esperado, prevaleceu aos 7 dias com numerosos polimorfonucleares, permeando o tecido de granulação (BOVISSON $\boldsymbol{e t} \boldsymbol{a l}$., 1988; FALANGA $\boldsymbol{e t} \boldsymbol{a l}$., 1988; KOOPMANN, 1995). As reações mais acentuadas foram encontradas nas lesões recobertas com a película biológica, porém, com exceção das feridas tratadas com poliuretano, ocorreu reação imunológica e presença de células gigantes esparsas. Aos 14 dias, todas as feridas, independentes do tratamento, estavam apenas parcialmente recobertas com epitélio, geralmente com hiperplasia da camada de células espinhosas, alongamento das cristas epidérmicas e hiper e paraceratose. Como evolução do processo cicatricial, o tecido de granulação apresentava-se maduro, com poucos vasos e raras células inflamatórias (DIEGELMANN $\boldsymbol{e} \boldsymbol{t} \boldsymbol{a l}$., 1981; KOOPMANN, 1995). A exceção do tratamento controle, todos os 
demais incitaram uma resposta granulomatosa, sendo que com os curativos poliuretano e hidrocolóide, esta reação foi mais discreta e traduzida por pequenos nódulos de células mononucleares e células gigantes, tipo corpo estranho, nas área mais profundas do conjuntivo. Com o curativo biológico, a reação granulomatosa foi intensa, com grandes acúmulos de células epitelióides, macrófagos e células gigantes, dispostas em nódulos ou em cunha. Provavelmente, estas reações estariam relacionadas com os componentes dos curativos. Aos 28 dias, prevaleceu o quadro de reepitelização completa da ferida e aceleração do processo cicatricial em todos os tratamentos, à exceção do biológico. Neste, o processo evoluiu para inflamação crônica granulomatosa profunda e inflamação aguda superficial, em resposta à ulceração da epiderme. Nos outros tratamentos, o desvio da evolução normal do processo, bem como o aparecimento de granulomas parecem ter ocorrido por fatores isolados.

\section{CONCLUSÃO}

O curativo hidrocolóide favorece a cicatrizacão de feridas abertas ocasionando redução acentuada da área da ferida nos primeiros sete dias, porém não há diferença significativa no período total de cicatrização quando comparado com o curativo de poliuretano, hemicelulose e vaselina com gaze.

\section{FONTES DE AQUISIÇÃO}

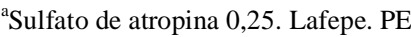

${ }^{b}$ Rompum. Lab. Bayer do Brasil. RJ

${ }^{c}$ Hypnomidade. Jassen Farmacêutica. SP

${ }^{\mathrm{d}}$ Pomada de vaselina. Granado. RJ

eDuoderm CGF. Convatec-Bristol-Myers Squibb Company. Canadá

${ }^{\mathrm{f}}$ Bioskin Produtos micro-biológicos Ltda. PB

${ }^{\mathrm{g}}$ Tegaderm. Produtos médicos para controle da infecção.3Mdo Brasil. SP

${ }^{\text {h }}$ Surgifix. Kors do Brasil. MG

${ }^{i}$ Flotril. Shering-Ploug. RJ

\section{REFERÊNCIAS BIBLIOGRÁFICAS}

ANDRADE, M., SEWARD, R., MELO, J. Curativos. Wound dressing. Rev Med Minas Gerais, v. 2, n. 4, p. 228-236, 1992.

ALGOWER, M. Manual de Cirurgia, Barcelona: Científicomédica, 1977, p. 3-14.

ANDERSON, D. Wound management in small animal practice In Practice., March, v. 18, p. 115-128, 1996.

BARBUL, A., CALDWELL, M., EAGLSTEIN, W. $\boldsymbol{e} \boldsymbol{t} \boldsymbol{a}$. Clinical and experimental approaches to dermal and epiderma repair. Normal and chronic wounds. Progress Clin Biol Ver. v. 365 , p. $257-265,1990$.
BOVISSON, H.,PIERAGGI, M., JULIAN, M. et al. Fibroblast in dermal tissue repair. Eletron microscopic and immunohistochemical study. Inter J Repair, v. 27, p. 564, 1988

BURRIDGE, K. Are stress fibers contractille? Nature, v. 294, p. 691, 1981.

CARRICO, T., MEHRHOF Jr.A., COHEN, I. Biology of wound healing. Surg Clin North Am, v. 64, n. 4, p. 721-727, 1984.

CHANDRASOMA, P., TAYLOR. Patologia básica. 2 ed. Hall do Brasil, 1993. p. 70-89.

CHAVPIL, M., HOLUBEC, M., CHAVPIL, B. Inert dessing is not desirable. J Am Podiatic Med Asso, v. 51, p. 245-252, 1990

CHOATE, C. Wound dressing. A comparison of classes and their principles of use. J Am Podiatic Med Asso, v. 84, n. 9, p. 463-469, 1994.

COCKBILL, S., TURNER, T. Management of veterinary wounds. Vet Rec, v. 136, p. 362-365, 1995.

DIEGELMANN, R., COHEN, K., McCOY, B. Growth kinectics and collagen syntesis of normal skin, normal scar and keloide fibroblast in vitro. J Cell Physiol, v. 98, p. 341-346, 1979.

FALANGA, V., ZITELLI, J., EAGLSTEIN, W. Wound healing. J Am Acad Derm, v. 19, n. 3, p. 559-563, 1988.

HUTCHINSON J., MacGUCKIN, M. Occlusive dressings: A microbiologic and clinical review. Am J Infect Control, v. 18, p. 257-268, 1990.

JETER, K., TINTLE, T. Wound dressing of the nineties: Indications and contraindications. Clin Podiat Med Surg, v. 8, n. 4, p. $799-816,1991$.

KOOPMANN, C. Cutaneous wound healing. Otolaryngologic Clin North Am, v. 28, n. 5, p. 835-845, 1995.

MADDEN, J., AREM, A. A cicatrização das feridas. Aspectos biológicos e clínicos. In: SABISTON, D. Tratado de Cirurgia. 14 ed. Rio de Janeiro: Guanabara Koogan, 1991. p. 156-168.

McGRATH, M. The effect of prostaglandin inhibitors on wound contraction and myofibroblast. Plastic Reconst Surg, v. 69, p. 74-83, 1982.

MODOLIN, M. Biologia da cicatrização dos tecidos. In MELEGA J., ZANINI S., PSILlAKIS, J. Cirurgia Plástica Reparadora e Estética. 2 ed. São Paulo: MEDSI, 1992. p. 925 .

MODOLIN, M., BEVILACQUA, R. Cicatrização das feridas. In: RAIA, A., ZERBINI, E. Clínica Cirúrgica Alípio Corrêa Neto. 4 ed. São Paulo: SARVIER, 1992. p. 133-138.

MORGAN, P., BINNINGTON, A., MILLER, C. et al. The effect of occlusive and semi-occlusive dressings on the healing of acute full-thickness skin wounds on the forelimbs of dogs. Vet Surg, v. 23, p. 494-502, 1994

POPE, E. Skin healing. In: BOJRAB, M. Diseases mechanismo in small animal surgery, 2 ed. London: Philadelphia, 1993. p. $152-155$ 
PRATA, M., HADDAD, C., GOLDENBERG, S. et al. Uso tópico do açúcar em ferida cutânea. Estudo experimental em ratos. Acta Cir Bra, v. 3, n. 2, p. 43-48, 1988.

RAMSEY, D., POPE, E., WAGNER-MANN, C. et al. Effects of three occlusive dressing materials on healing of full-thickness skin wounds in dogs. Am J Vet Res, v. 56, n. 7, p. 941-949, 1995.
RUNGGER-BRANDLE, E., GABBIANI, G. The role of cytoskeletal and cytocontractile elements in pathologic process. Am J Path, v. 4, p. 763, 1983.

STRACHAN, D. Topical theraphy of wounds, Aust Vet Pract, v. 25, n.1, 1996.

VAN WINKLE JR., W. Wound contraction. Surg Ginecol Obst, v. 125, p. $131-142,1967$.

Ciência Rural, v. 29, n. 2, 1999. 